\title{
Monoclonal antibodies to human sperm antigens
}

\author{
Chi-Yu Gregory Lee ${ }^{1}$, Yuan-Shen Huang ${ }^{2}$, Chien-Hwai Huang ${ }^{2}$, \\ Ping-C. $\mathrm{Hu}^{2}$ and Alan C. Menge ${ }^{3}$ \\ ${ }^{I}$ Department of Obstetrics and Gynaecology, University of Brittsh Columbia, Vancouver, Canada, ${ }^{2}$ Cancer \\ Research Center, University of North Carolina, Chapel Hill, N.C. and ${ }^{3}$ Department of Obstetrics and \\ Gynecology, University of Michigan Medical Center, Ann Arbor, Mich., U.S.A.
}

(Received 16 December 1981; revised 28 January 1982; accepted 22 February 1982)

To elucidate the molecular nature of human sperm autoantigens, attempts were made to raise monoclonal antibodies against these antigens by hybridoma techniques. After successive immunizations with the particulate fractions of human sperm extract in BALB/c mice, the spleen cells were fused with P3-X63-Ag8 myeloma cells. Several clones and their subclones were obtained and shown by microplate radioimmunoassay to produce antibodies against human sperm antigens. When SDS gel/protein blot radioimmunobinding was used for further molecular analysis, three independently derived clones were shown to produce antibodies, all of which cross-reacted with the same two human sperm antigens with a molecular weight of about 10000 . Using an indirect immunofluorescence assay, antibodies produced by these clones were shown to react with antigens localized on the acrosomal regions of human spermatozoa. Monoclonal antibodies produced by other clones, however, showed no cross-reactivity with any of the blotted proteins from SDS gels of human spermatozoa. Some possible reasons for this are presented.

\section{Introduction}

It has been known for many years that male animals injected with homologous spermatozoa can produce autoantibodies against these cells (Freund et al., 1953; Bishop and Carlson, 1965; Voisin and Toullet, 1971; Voisin et al., 1974). Such autoimmune responses often result in the development of experimental allergic orchitis in animals such as the guinea pig (Brown and Glynn, 1969; Voisin and Toullet, 1971). Numerous attempts have been made to isolate and characterize the sperm autoantigens that elicit antisperm antibodies in experimental animals or in humans (Freund et al., 1953; Katsh et al., 1972; Voisin et al., 1974; Jackson et al., $1975 \mathrm{a}, \mathrm{b}$ ). Most of these autoantigens are localized on the surface of spermatozoa and are of protein or glycoprotein nature (Jackson et al., 1975b).

In humans, the occurrence of antisperm antibodies may be associated with male or female infertility (Rümke and Hellinga, 1959; Shulman, 1971; Rümke et al., 1974). One of the causes for the formation of antisperm antibodies could be the resorption of spermatozoa, as for instance occurring after vasectomy (Ansbacher, 1973). There is also a growing interest in the possibility of using purified autoantigens of human spermatozoa as vaccines for immunological contraception (Stevens, 
1976). By indirect immunofluorescence assay, at least eight sperm autoantigens have been localized on human spermatozoa (Hansen and Hjort, 1971; Tung, 1975) but little is known of the chemical and molecular nature of these autoantigens.

In order systematically to characterize human sperm antigens, especially the autoantigens, attempts have recently been made to raise monoclonal antibodies against the antigens by using the hybridoma technique of Köhler and Milstein (1975). The development of hybrid cell lines secreting monoclonal antibodies to individual antigens of human spermatozoa is important for a better identification and characterization of sperm antigens. Moreover, the production of monoclonal antibodies to sperm autoantigens may be essential for their large scale purification by affinity chromatography and for applications in immunological contraception. Monoclonal antibodies to different sperm antigens may also be of value for investigation of the association between infertility and antisperm antibodies.

SDS gel/protein blot radioimmunobinding has been employed as a sensitive tool for the immunological identification of specific antigens which are renatured and transferred from the SDS gels to nitrocellulose filters (Sharon et al., 1979; Towbin et al., 1979; $\mathrm{Hu}$ et al., 1981; Lee et al., 1982). In this communication, we report the production of monoclonal antibodies specific to human sperm antigens and their initial characterization by SDS gel/protein blot radioimmunobinding.

\section{Materials and Methods}

Animals

Male mice of BALB/c strain, 8-10 weeks old, were purchased from the Jackson Laboratory, Bar Harbor, Maine.

\section{Chemicals}

All the analytical grade reagents for acrylamide gel electrophoresis were from Bio-Rad. Nitrocellulose filters were from Millipore. Polyethylene glycol 1000, gelatin, Agamma horse serum, dimethyl sulfoxide and chloramine $T$ were from Sigma. Nonidet P-40 and cellulose pad were from Bethesda Research Laboratory. Aminopterin, 8-azaguanine, hypoxanthine, phenylmethyl sulfonyl fluoride and thymidine were from Sigma.

\section{Cell lines and media}

Myeloma cell lines, P3-X63 Ag8, were maintained in the presence of $20 \mu \mathrm{g} / \mathrm{ml}$ of 8-azaguanine. All hybrid cell lines were grown in Dulbecco's modified Eagle's medium with glucose $(4.5 \mathrm{mg} / \mathrm{ml})$ (Gibco, Grand Island, N.Y.), $20 \%$ heat-inactivated fetal calf serum and $5 \% \mathrm{CO}_{2}$ at $37^{\circ} \mathrm{C}$.

\section{Immunization, cell fusions and cloning}

Frozen human semen $(10 \mathrm{ml})$, from pooled samples obtained from healthy donors at North Carolina Memorial Hospital, N.C., was thawed and centrifuged at $1000 \times \mathrm{g}$ for $10 \mathrm{~min}$. The pellet was resuspended in $10 \mathrm{ml}$ phosphate buffered saline (PBS) 
and sonicated for $1 \mathrm{~min}$ at 10 -s intervals. The sonicated sperm extract was centrifuged at $27000 \times \mathrm{g}$ for $20 \mathrm{~min}$. The precipitate was washed once with $10 \mathrm{ml}$ PBS followed by resuspension and centrifugation as above. The pellet was frozen at $-40^{\circ} \mathrm{C}$ for use later in the immunization of mice and rabbits.

The frozen pellet of sonicated human spermatozoa was thawed in PBS containing $1 \%$ NP-40 (final protein concentration of $1 \mathrm{mg} / \mathrm{ml}$ ) and emulsified with an equal volume of complete Freund's adjuvant. Two BALB/c mice were injected intraperitoneally with $1 \mathrm{mg}$ each of antigen in $0.2 \mathrm{ml}$ on days 1,15 and 29 . On day 36, immunized mice were bled to check the immune response by microplate radioimmunoassay (described below). On day 39, the mice were boosted through the tail vein with $1 \mathrm{mg} / \mathrm{ml}$ of sperm antigen in $50 \mu 1$ PBS containing 1\% NP-40. Three days after the boosted immunization the spleen was removed separately from each mouse and fused with P3-X63 Ag8 myeloma cells at a ratio of $1: 1$. The cell fusion was carried out in the presence of 50\% polyethylene glycol 1000 in Dulbecco's modified Eagle's medium (Köhler and Milstein, 1975) in $2 \mathrm{~min}$. The fused cells were seeded into 96 wells of standard culture plates (cell density of $10^{6}$ cells/well) and cultured in HAT (hypoxanthine/aminopterin/thymidine) selective medium (Köhler ànd Milstein, 1975). During the first two weeks, almost all the unfused spleen cells and myeloma cells died. The hybridized cells were then cultured for 7 days in medium containing hypoxanthine and thymidine. Three weeks after the cell fusion only 6 wells contained viable clones. Cultures secreting antibodies were further cloned in soft agar: a total of eight different hybrid cell lines were cloned or subcloned and shown to secrete antibodies against human sperm antigens as judged by microplate radioimmunoassay (Voller et al., 1979).

$1 \mathrm{ml}$ each of the positively identified hybrid cells at a density of $10^{6}$ cells $/ \mathrm{ml}$ was injected intraperitoneally into BALB/c mice for 7 to 10 days. The ascites fluid was drawn from each mouse and the monoclonal antibodies were recovered by centrifugation at $27000 \times \mathrm{g}$ for $10 \mathrm{~min}$ to remove cell debris. The supernatant containing a high concentration of monoclonal antibody was stored at $-20^{\circ} \mathrm{C}$. All cultures were frozen in liquid $\mathrm{N}_{2}$ medium containing $50 \%(\mathrm{v} / \mathrm{v})$ fetal calf serum and $10 \%(\mathrm{v} / \mathrm{v})$ dimethyl sulfoxide. The cloned hybrid cell lines and their secreted antibodies were coded with the initials HS and given numbers to define each mouse and culture, respectively.

\section{Antisperm antisera}

Mouse and rabbit antisera against human sperm antigens were prepared by immunization with the particulate fraction of human spermatozoa. Briefly, BALB /c mice were injected subcutaneously bi-weekly with about $100 \mu \mathrm{g}$ of the sonicated human sperm pellet in $0.1 \mathrm{ml}$ PBS containing 1\% NP-40 homogenized with $0.1 \mathrm{ml}$ complete Freund's adjuvant. The mice were bled one week after the third injection. The same immunization scheme was used for rabbits except that $10 \mathrm{mg}$ of immunogen in $1 \mathrm{ml}$ of PBS/adjuvant mixture $(1: 1 \mathrm{v} / \mathrm{v})$ was used, and the animals were bled after 7 weeks. The sera were recovered by centrifugation at $2000 \times \mathrm{g}$ for $10 \mathrm{~min}$ and stored at $-20^{\circ} \mathrm{C}$. Goat anti-mouse IgG and goat anti-rabbit IgG (Miles Laboratory) were purified according to published procedures (Levy and Sober, 1960; Miller and 
Stone, 1978) and labelled with ${ }^{125} \mathrm{I}$ using the chloramine T method (Greenwood and Hunter, 1963).

\section{Microplate radioimmunoassay}

This assay was performed according to the method of Voller et al. (1979) except that ${ }^{125}$ I-labelled goat anti-mouse IgG was used instead of enzyme-linked goat anti-mouse IgG. Briefly, to examine the specificity of antibodies produced by the hybrid cell lines, the human spermatozoal pellet was recovered after sonication by centrifugation, solubilized with $1 \%$ NP-40, and then suspended in the wells of microtiter plates with carbonate buffer containing $1.59 \mathrm{~g} / 1 \mathrm{Na}_{2} \mathrm{CO}_{3}, 2.93 \mathrm{~g} / 1$ $\mathrm{NaHCO}_{3}, 0.2 \mathrm{~g} / 1 \mathrm{NaN}_{3}$ and $0.5 \mathrm{ml} / 1$ Tween-20. After overnight to $24 \mathrm{~h}$ incubation at $4^{\circ} \mathrm{C}$, the plates were washed three times with PBS-Tween $(8.0 \mathrm{~g} / 1 \mathrm{NaCl}, 0.2 \mathrm{~g} / 1$ $\mathrm{KH}_{2} \mathrm{PO}_{4}, 2.9 \mathrm{~g} / 1 \mathrm{Na}_{2} \mathrm{HPO}_{4}, 0.2 \mathrm{~g} / 1 \mathrm{NaN}_{3}$ and $0.5 \mathrm{ml} / 1$ Tween-20) containing $2 \%$ agamma horse sera. Mouse anti-human sperm sera or anti-human sperm monoclonal antibodies (ascites fluid or supernatant of the hybrid cells cultures) were added in different dilutions (in PBS-Tween) to wells coated with human sperm antigens in microplates. After $18 \mathrm{~h}$ at $4^{\circ} \mathrm{C}$, the wells were washed three times with PBS-Tween, followed by incubation with ${ }^{125} \mathrm{I}$-labelled goat anti-mouse IgG. After $2 \mathrm{~h}$ at $37^{\circ} \mathrm{C}$, unreacted or excess ${ }^{125} \mathrm{I}$-labelled anti-IgG was removed by aspiration and the wells washed three times with PBS-Tween containing $2 \%$ agamma horse serum. The radioactivity retained in each well of microplates was determined by using a Beckman gamma counter (Model 4000).

\section{SDS gel/protein blot radioimmunobinding}

Human sperm antigens that cross-react with mouse anti-human sperm monoclonal antibodies were analyzed by SDS gel/protein blot radioimmunoassay. The details of this assay have been described elsewhere (Hu et al., 1981; Lee et al., 1982). Sodium dodecylsulfate acrylamide gel electrophoresis was performed according to the procedure of Laemmli (1970). To prepare the running gels, $10 \%$ acrylamide and $0.1 \%$ sodium dodecylsulfate were used. For comparisons, SDS gels of human sperm samples were prepared either with or without $\beta$-mercaptoethanol. After protein blot, human sperm antigens specific to monoclonal antibodies were visualized on strips of nitrocellulose filters by autoradiography, developed with Kodak X-omat films.

\section{Indirect immunofluorescence}

The immunofluorescent staining was performed on methanol-fixed human spermatozoa according to the procedure outlined by Johnson and Menge (1975), using PBS, normal mouse serum (diluted $1: 10$ ), control mouse ascites fluid and two monoclonal antibodies against human sperm. The labelled antibody was rabbit anti-mouse IgG conjugated with fluorescein isothiocyanate (Miles Labs). Slides were observed under dark field illumination with a Zeiss photomicroscope equipped with a halogen-quartz light system and appropriate filters. 


\section{Results}

Three weeks after cell fusions, more than a dozen independently derived clones were produced from two mice immunized with human sperm antigens. Among them, six clones (HS-202, HS-203, HS-204, HS-206, HS-208, HS-301) were shown to secrete antibodies that reacted with human sperm antigens, as judged by microplate radioimmunoassay with the supernatant of the culture fluid from each hybrid cell line. By the same radioimmunoassay, subclonings of the hybrid cell lines revealed a total of eight different sublines that secreted anti-human sperm antibodies (HS-202-6, HS-203-9, HS-203-10, HS-204-2, HS-206-1, HS-206-2, HS-208-5, HS-301-1). The antibody titers for clones HS-206-1 and HS-206-2 are presented in Fig. 1. To identify the molecular nature of human sperm antigens that elicit monoclonal antibodies from different hybrid cell lines derived from initial clonings and subclonings, SDS gel/protein blot radioimmunobinding was employed. As shown in Fig. 2 , in the presence of the reducing agent, $\beta$-mercaptoethanol, for SDS gel of human sperm samples, SDS gel/protein blot radioimmunobinding was performed for each hybrid cell line secreting monoclonal antibodies. The same two adjacent human sperm antigens with the molecular weight of about 10000 were recognized by monoclonal antibodies secreted from clones HS-203, HS-206 and HS-301 and some of their subclones (HS-206-1, HS-206-2, HS-203-9, HS-203-10). On the contrary, no specific sperm antigens were identified to cross-react with other initially derived hybrid cell lines (HS-202, HS-204, HS-208) and their subclones.

As a control, the same assay was applied to the analysis of anti-human sperm antisera raised in mice and rabbits. As can be seen from Fig. 2, most of the human

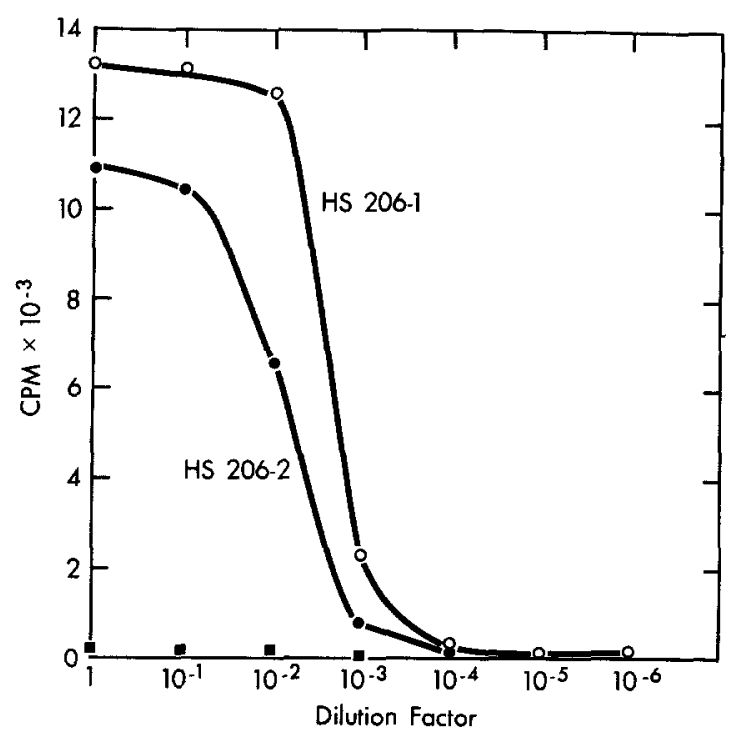

Fig. 1. Microplate radioimmunoassays showing the titers of monoclonal antisperm antibody derived from ascites fluid of clones HS-206-1 (O) and HS-206-2 (O). represents that of the non-immune mouse sera. 


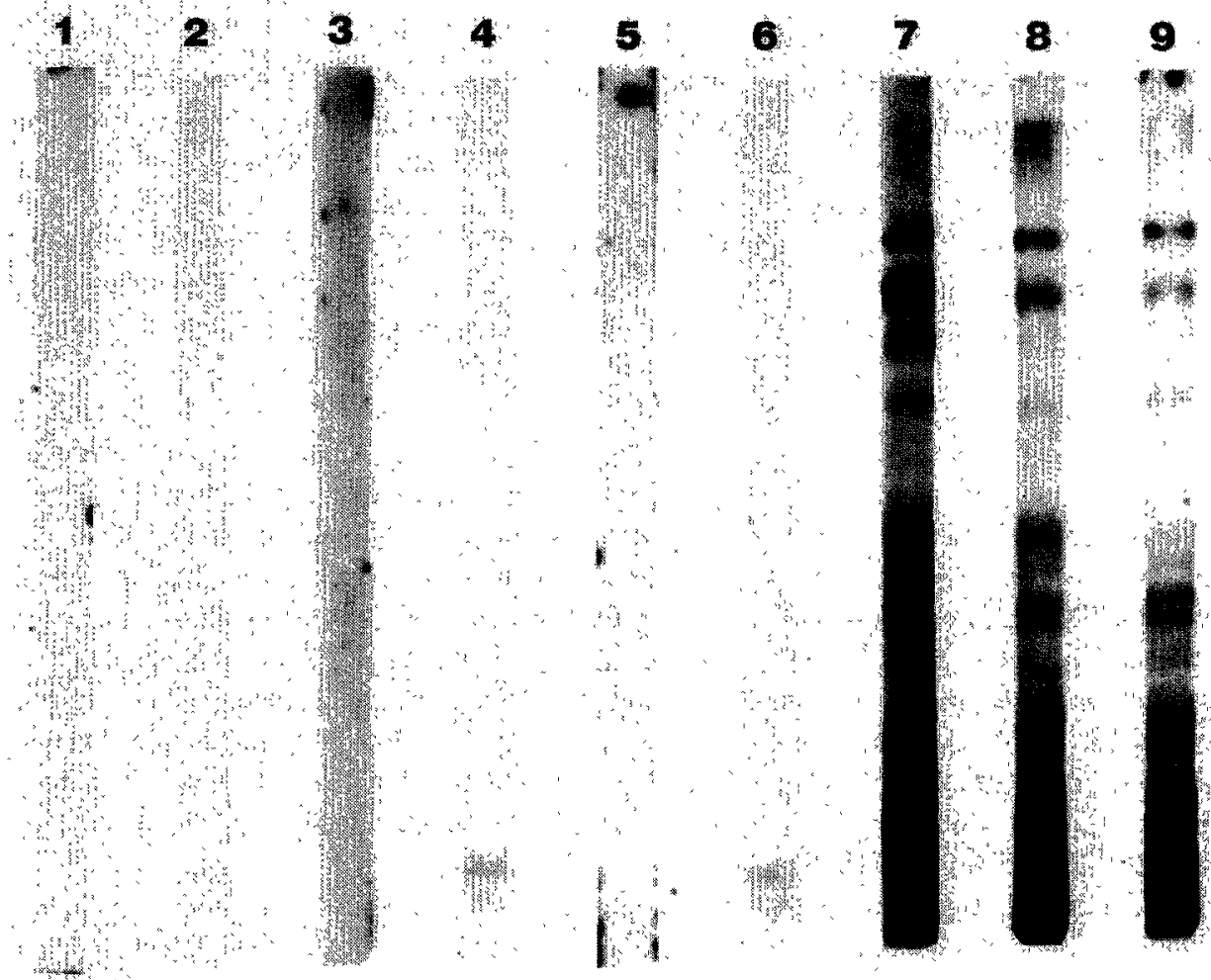

Fig. 2. Autoradiogram showing human sperm antigens that react with monoclonal antibodies from different hybrid cell lines by SDS gel/protein blot radioimmunobinding. Lane 1: Monoclonal antibody from clone HS-202-6 (24 h exposure). Lane 2: Monoclonal antibody from clone HS-203-9 ( $6 \mathrm{~h}$ exposure; with culture fluid supernatant 1:5 dilution). Lane 3: Monoclonal antibody from clone HS-204-2 (24 h exposure). Lane 4: Monoclonal antibody from clone HS-206-1 (6 h exposure; with ascitic fluid 1:500 dilution). Lane 5: Monoclonal antibody from clone HS-208-5 (24 h exposure; with culture supernatant 1:5 dilution). Lane 6: Monoclonal antibody from clone HS-301-1 (6 h exposure; with culture supernatant 1:5 dilution). Lane 7: Rabbit anti-human sperm antiserum (1:500 dilution; $6 \mathrm{~h}$ exposure). Lane 8: Rabbit anti-human sperm antiserum (1:500 dilution; immunization in the presence of $1 \%$ Triton X-100 with adjuvant; $6 \mathrm{~h}$ exposure). Lane 9: Mouse anti-human sperm antiserum (1:500 dilution; $6 \mathrm{~h}$ exposure).

sperm proteins that are transferred from SDS gels to nitrocellulose strips are antigenic in mouse and in rabbit. Some difference in immune response was observed when the sperm antigens were immunized in the presence of $1 \%$ Triton X-100.

Indirect immunofluorescent staining with monoclonal antibodies from HS-206-1 and HS-206-2 revealed a bright, diffuse pattern covering the acrosomal area of the spermatozoa. The control samples gave negative results. These two monoclonal antibodies did not reveal any complement-dependent cytotoxicity on human spermatozoa as demonstrated by the micro-Isojima test (Menge, 1980). 


\section{Discussion}

In this study, attempts were made to produce monoclonal antibodies against human sperm antigens by the hybridoma technique. Two sensitive radioimmunoassay/binding methods were used to examine the general specificity of antibodies secreted by the hybrid cell lines and to identify the molecular nature of the specific human sperm antigens. Microplate radioimmunoassay allows a fast detection of hybrid cell lines that secrete antibodies and SDS gel/protein blot radioimmunobinding provides a sensitive method for the identification of specific human sperm antigens that react with the monoclonal antibodies.

Unexpectedly three of the six independently derived hybrid cell lines were shown to produce antibodies that react with two human sperm antigens having a close molecular weight of about 10000 . However, the antibodies secreted by the other three hybrid cell lines did not recognize any proteins that were renatured from SDS gels transferred to nitrocellulose strips. On the other hand, these three hybrid cell lines were shown by the microplate radioimmunoassay to secrete antibodies that cross-reacted with particulate fractions of human spermatozoa extract in 1\% NP-40. A number of possibilities can be offered to explain such a discrepancy. SDS gel/protein blot radioimmunobinding detects immunologically the renatured proteins that are not in aggregated or disulfide-linked states. If the antibodies secreted by these hybrid cell lines recognize only the conformational determinants of those proteins which are in aggregated states they may not be able to react with individually renatured proteins from SDS gels. It is also possible that these antibodies react only with those sperm proteins that cannot be renatured and transferred to nitrocellulose filters under our experimental conditions. Finally, one cannot rule out the possibility that the monoclonal antibodies generated by these hybrid cell lines are not of the IgG class or that they do not have enough affinity to the sperm proteins on nitrocellulose strips, so that no evidence of antigen-antibody binding could be demonstrated by this particular assay.

The monoclonal antibody secreted by clones HS-206-1 and HS-206-2 was employed in indirect immunofluorescence assays and produced a bright, diffuse staining pattern covering the acrosomal area of the spermatozoa. This clearly indicates that the low molecular weight sperm antigens that react specifically with this monoclonal antibody are preferentially localized on the acrosomal surface of human spermatozoa.

By using the SDS gel/protein blot radioimmunobinding method, the specificity of the monoclonal antibodies that recognize the low molecular weight sperm antigens was examined. So far, we have not been able to identify the same antigens in human erythrocytes and seminal plasma with these antibodies, indicating that the identified human sperm antigens may be sperm-specific. Further studies are in progress to investigate the effects of these monoclonal antibodies on the behaviour of human spermatozoa. 


\section{Acknowledgement}

This study was supported in part by a research grant No. 5-(81-1) to C.-Y. Lee and V. Gomel from the B.C. Health Care and Research Foundation.

\section{References}

Ansbacher, R. (1973) Vasectomy: Sperm autoantibodies. Fertil. Steril. 24, 788.

Bishop, D.W. and Carlson, G.L. (1965) Immunologically induced aspermatogenesis in guinea pig. Ann. N.Y. Acad. Sci. 124, 247.

Brown, P.C. and Glynn, L.E. (1969) The early lesion of experimental allergic orchitis in guinea pigs. J. Pathol. 98, 277.

Freund, J., Lipton, M.M. and Thompson, G.E. (1953) Aspermatogenesis in guinea pig induced by testicular tissues and adjuvants. J. Exp. Med. 97, 711.

Greenwood, F.C. and Hunter, W.M. (1963) The preparation of $I^{131}$-labelled human growth hormone of high specific radioactivity. Biochem. J. 99, 114.

Hansen, B.K. and Hjort, T. (1971) Immunofluorescent studies on human spermatozoa. II. Characterization of spermatozoal antigens and their occurrence in spermatozoa from male partners of infertile couples. Clin. Exp. Immunol. 9, 21.

Hu, P.C., Huang, Y.-S., Graham, J.A, and Gardner, D.E. (1981) Identification of immunogens of Mycoplasma pneumoniae by protein plotting. Biochem. Biophys. Res. Commun. 103, 1363.

Jackson, J.J., Hagopian, A., Carlo, D.J., Limjuco, G.A. and Eyler, E.H. (1975a) Experimental allergic aspermatogenic orchitis. I: Isolation of a spermatozoal protein (API) which induces allergic aspermatogenic orchitis. J. Biol. Chem. 250, 6141.

Jackson, J.J., Hagopian, A., Carlo, D.J., Limjuco, G.A. and Eylar, E.H. (1975b) Experimental allergic and aspermatogenic orchitis. II: Some clinical properties of API protein of the sperm acrosome. Biochem. Biophys. Acta 427, 251.

Johnson, L.W. and Menge, A.C. (1975) Evaluation of human sera for antibodies against sperm by indirect immunofluorescence. Fertil. Steril. 26, 712.

Katsh, S., Aguire, A.R., Leaver, F.W. and Katsh, G.F. (1972) Purification and partial characterization of aspermatogenic antigens. Fertil. Steril. 23, 644.

Köhler, G. and Milstein, C. (1975) Continuous cultures of fused cells secreting antibodies of predefined specificity. Nature (London) 256, 495.

Laemmli, U.K. (1970) Cleavage of structural proteins during the assembly of the head of bacteriophage $\mathrm{T}_{4}$. Nature (London) 227, 680 .

Lee, C.-Y.G., Huang, Y.-S., Hu, P.-C., Gomel, V. and Menge, A.C. (1982) Analysis of sperm antigens by SDS gel/protein blot radioimmunobinding method. Anal. Biochem. (in press).

Levy, H.B. and Sober, H.A. (1960) A simple method for the chromatographic preparation of gamma globulin. Proc. Soc. Exp. Biol. Med. 103, 50.

Menge, A.C. (1980) Clinical immunologic infertility: Diagnostic measures, incidence of antisperm antibodies, fertility and mechanism. In Immunological Aspects of Infertility and Fertility Regulation (Dhindsa, D.S. and Schumacher, G.F.B., eds.), pp. 205-224. Elsevier/North-Holland, Amsterdam.

Menge, A. and Peegel, H. (1980) Antibody activities of serum and uterine fluid samples from rabbits isoimmunized against sperm fractions. Arch. Androl. 4, 171-178.

Miller, T.J. and Stone, H.O. (1978) The rapid isolation of ribonuclease-free immunoglobulin by protein A-Sepharose affinity chromatography. J. Immunol. Methods 24, 111.

Rümke, P. and Hellinga, G. (1959) Autoantibodies against spermatozoa in sterile men. Am. J. Clin. Pathol. 32, 357.

Rümke, P., Van Amstel, N., Messer, E.N. and Bezemer, P.D. (1974) Prognosis of fertility of men with sperm agglutinins in the serum. Fertil. Steril. 25, 393.

Sharon, J., Morrison, S.L. and Kabat, E.A. (1979) Detection of specific hybridoma clones by replica 
immunoadsorption of their secreted antibodies. Proc. Natl. Acad. Sci. U.S.A. 76, 1420.

Shulman, S. (1971) Antigenicity and autoimmunity in sexual reproduction. Clin. Exp. Immunol. 9, 267.

Stevens, V.C. (1976) Immunological approaches to fertility regulation. Bull. W.H.O. 56, 179.

Towbin, H., Staehelin, T. and Gordon, J. (1979) Electrophoretic transfer of proteins from polyacrylamide gels to nitrocellulose sheets: Procedure and some applications. Proc. Natl. Acad. Sci. U.S.A. 76, 4350.

Tung, K.S.K. (1975) Human sperm antigens and antisperm antibodies. I. Studies on vasectomized patients. Clin. Exp. Immunol. 20, 93.

Voisin, G.A. and Toullet, F. (1971) Aspermatogenic orchitis: A model for three possible mechanisms of autoimmune lesions. Folia Allergol. 18, 310.

Voisin, G.A., Toullet, F. and D'Almeida, M. (1974) Characterization of spermatozoal, auto-, 1so-, and allo-antigens. Karolinska Symp. Res. Methods Reprod. Endocrinol. 7, 173.

Voller, A., Bidwell, D. and Bartlett, A. (1979) The enzyme linked immunosorbent assay (ELISA), Dynatech Labor tories, Inc., pp. 35-42. 